\title{
REALIDADE E FICÇÃO NO DISCURSO TELEVISIVO
}

\author{
Elizabeth Rondelli ${ }^{*}$
}

Oh, Richardson! ousarei dizer que a história mais verdadeira é cheia de mentiras e que teu romance é cheio de verdades. A história pinta alguns indivíduos: tu pintas a espécie humana; a história atribui a alguns indivíduos o que não disseram nem fizeram; tudo o que atribui ao homem, ele assim fez; a história abarca apenas uma porção de tempo, apenas um ponto da superfície do globo: tu abrangeste todos os lugares e todos os tempos. O coração humano, que foi, é e sempre será o mesmo, eis o modelo segundo o qual copias. ${ }^{1}$

\section{Os sotaques}

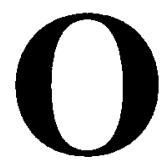

ingresso das tevês a cabo e por assinatura no Brasil aumentou a transmissão de programas televisivos produzidos em outros países, além dos filmes e de outros gêneros que cotidianamente circulavam pelas emissoras broadcast.

Esta presença tem evidenciado não só o crescimento de um mercado televisivo mundialmente em constante expansão, o que torna o Brasil um dos lugares importantes para se pensar a produção cultural contemporânea, como tem evidenciado que a televisão brasileira, assim como qualquer outra televisão nacional, possui um determinado sotaque, ou seja, um modo peculiar de falar

* Universidade Federal do Rio de Janeiro (e-mail: rondelli @cfch.ufrj.br)

1 DIDEROT, Denis. Ouvres esthéthiques. Paris: Garnier, 1968. p. 39-40. 
que a distingue da programação televisiva de outros países. Como se, a um meio técnico e de produção semelhante, a programação televisiva respondesse com padrões de cultura e de linguagem diferenciais que constroem toda uma ambiência definidora de uma certa personalidade local ou regional. Por isso, telespectadores mais atentos podem perceber diferenças entre um filme brasileiro e um europeu, assim como podem distinguir uma notícia editada pela televisão americana de uma brasileira, por exemplo, apesar de estar ocorrendo uma certa homogeneização, em níveis quase mundiais, da produção e do consumo televisivos.

Se a linguagem e os recursos técnicos da televisão são razoavelmente semelhantes em todo o lugar em que esta se apresenta, podemos inferir que estes sinais de distinção emergem porque a televisão, em suas formas peculiares de realização, transita e negocia de modos específicos com a realidade na qual seus produtores se inspiram. Como também se dirige de modo muito próprio ao seu público telespectador, sempre culturalmente diferenciado, apesar de estar inserido num processo de crescente globalização cultural. Toda a televisão nacional tem, portanto, sua pronúncia original, como toda emissora tem seus cacoctes e acentos característicos por mais rede global que se pretenda.

Dois exemplos destas marcas: embora a televisão brasileira tenha copiado alguns modelos de programação da televisão européia, da latinoamericana e, principalmente, da norte-americana, ela produziu o seu próprio estilo. De um híbrido entre o seriado ou telefilme americano e as telenovelas latino-americanas, ela construiu o seu próprio modo de produzir ficção, mais próximo das nossas maneiras de nos pensarmos culturalmente. Com isso, as pessimistas previsões, feitas no período da implantação da televisão no país, de que teríamos uma programação quase totalmente importada, não foram necessariamente cumpridas. Outro exemplo, este de caráter mais regional, está nas diferenças de programação e de estilo da Globo e do SBT, aquela notoriamente carioca, apesar de suas tentativas de se aproximar do mercado e dos telespectadores paulistas, e esta com um jeito notadamente mais paulista de ser. É claro que ambas refletem o fato de estarem localizadas no Rio e em São Paulo, respectivamente, o que faz com que o próprio local de recrutamento dos seus produtores, ou intermediários culturais, como propõe Bourdieu, permita trazer as marcas regionais nos gêneros e estilos da programação e produzir alguma identificação com os telespectadores aos quais se dirigem. Com base nestes argumentos, podemos imaginar que uma emissora cuja produção fosse sediada no nordeste do país teria algo característico e diferenciado para oferecer.

Na programação televisiva, o que temos, na maior parte das horas, são programas de produção nacional, sendo estes, normalmente, os de maior audiência. São, portanto, programas confeccionados por produtores culturais aqui 
nascidos e criados, cuja base de reflexão e de inspiração é o próprio país, seu povo, suas imagens e temas. Há, é certo, uma hegemonia regional paulista e carioca comandando a lista de emissoras e produtores, mas mesmo estes sentem-se obrigados a fazer uma televisão dirigida aos receptores de todo o país, de modo que brasileiros possam se reconhecer na tela. A estratégia do programa Você Decide de gravar a consulta a telespectadores reunidos alternadamente, a cada programa, nas praças de várias cidades do país, é um exemplo dessa busca de identificação e reconhecimento.

Por isso, a realidade, mal ou bem referida nesses programas, é esta nacional, local, regional, que não deixa de aludir a outras realidades à medida que os produtores e os produtos culturais, como é o caso dos programas televisivos, são informados pelo consumo de outras estéticas e expressões culturais estrangeiras. Nosso principal contato com as culturas norte-americana e européia, por exemplo, tem se dado através da literatura, do cinema e da televisão, com tudo o que esta consegue transmitir. É através desses meios e linguagens que o imaginário de um país é povoado pelas imagens do que sejam outros povos, países, costumes e culturas - uma espécie de "nunca te vi, sempre te amei", pelo qual o telespectador é atraído, por exemplo, nos filmes documentários exibidos na televisão, verdadeiras etnografias mediáticas.

Nesse sentido, estamos um pouco distantes da compreensão de que o reino das imagens seja povoado só de simulacros, realidades sem referentes, e mais próximos de aceitar que as realidades são apropriadas pelos produtores culturais, numa busca de diálogo constante com seus potenciais receptores. Estes, para produzirem os efeitos de ficção, de realidade ou mesmo de simulação do real, precisam ter alguns parâmetros comuns sobre o que é esta realidade a partir da qual se arquiteta qualquer discurso.

Quero extrair destes exemplos a afirmação de que na programação televisiva, assim como na literatura ou no cinema, a realidade, ou mais exatamente os modelos socioculturais sobre o que seja ou não a realidade, estão presentes, referenciados, referidos, para serem mostrados, analisados, criticados, ou para que se instituam, a partir deles, imaginários outros, fantasias ou mesmo delírios criativos.

Entretanto, se a literatura e o cinema são entendidos como pertencentes à ordem do discurso ficcional, apesar de vez ou outra produzirem alguns desvios como romances históricos, biográficos, ou filmes documentários, a televisão, por ser sobretudo um meio de transmissão que comporta vários níveis e estilos de linguagem, aparece como o lugar, por excelência, do cruzamento e da interação cotidiana, entre várias coisas, da realidade e da ficção.

Enquanto no livro literário e no filme criado para exibição no cinema obras ficcionais ou não-ficcionais são potencialmente recebidas e fruídas de 
modo autônomo e isolado, nos programas expostos na grade da programação televisiva, estes dois momentos - o da ficção e o da realidade - convivem lado a lado e diacronicamente num mesmo canal, ou simultânea e sincronicamente em alguns canais que o telespectador percorre rapidamente através do zapping. ${ }^{2}$

\section{Os gêneros ficcionais em busca dó real}

Os diversos gêneros dos discursos televisivos, ao se construírem, tomam o real como referência para, sobre ele, produzirem aproximaçōes ficcionais ou jornalísticas. No caso da televisão, os telejornais e documentários deveriam ser o reino dos discursos sobre o real, enquanto as telenovelas e seriados, o lugar da fỉç̧ão.

Entretanto, esses gêneros, além de não serem puros no modo cómo narrativamente constroem suas representações, convivem com uma série de outros gêneros que transitam entre os dois pólos sem nenhum compromisso de serem fiéis ou coerentes com a realidade ou com a ficção, e que ficam mergulhados numa região cinzenta. ${ }^{3}$

Sem pretender traçar uma complexa tipologia dos gêneros televisivos, cabe ressaltar aqui este trânsito, que talvez só à televisão seja permitido, de tratar temas a partir de programas inspirados em vários gêneros de linguagem ou de construção narrativa, de modo que nela muitas das fronteiras entre o real e 0 ficcional se dissipem.

Em trabalho anterior, cujo título, "A produção ficcional televisiva como artefato de construção do real", 4 sugere esta intenção de analisar como estes discursos entre o real e o ficcional se contagiam, constatei que, ao se traçar uma história das temáticas abordadas pelas telenovelas e seriados nacionais, evidencia-se a representação daquilo que para efeitos da produção ficcional televisiva se considera ser a realidade brasileira, nos seus aspectos rurais, urbanos, regionais, metropolitanos, históricos. Neste sentido, demonstrei como

2 Para avaliar os impactos que a invenção e o uso do controle remoto produziram na relação do telespectador com a programação televisiva, ver ALSINA, Miquel Rodrigo y. Los modelos de la commicacion. Madrid: Tecnos, 1989.

3 Conforme Buonanno, ao tratarmos das relaçōes entre ficçāo e noticias estamos diante de um jogo, de um system of bidirectional cross-references. BUONANNO, Milly. News-values and fiction values: news as serial device and criteria of "fictionworthiness" in Italian television fiction. Europecan Journal of Communication, v. 8, n. 2, 1993, p. 177-202.

4 RONDELLI, Elizabeth. A produção ficcional televisiva como artefato da construção do real. Communicuf̧ãod\&Políica, Rio de Janeiro, v. 21, 1992. 
telenovelas e seriados nacionais perseguiram alguns dos objetivos estéticoculturais das escolas literárias romântica e realista, e não por acaso muitas obras de autores dessas escolas foram retomadas para adaptação televisiva. Tendência que se apresenta como um continuum desde as telenovelas dos anos 60 e 70 , adaptadas das obras românticas e realistas do século XIX principalmente, às séries e minisséries trazidas dos autores literários contemporâneos dos anos 50 a 90 , adaptações até hoje recorrentes de maneira esparsa na programação. Tais adaptações são, entre outras coisas, um recurso para se construir identidades e, no caso, a identidade brasileira, o que nos soa antigo, porém novo por causa da forma e do veículo em que se manifesta. Isto nos levou a indagar sobre o paradoxo de um produto da cultura industrial que, ao se internacionalizar no circuito da distribuição, recorre à exploração das características culturaị regionais específicas e, por vezes, exóticas do país.

A representação naturalista, a tendência de mostrar o mundo como um puro dado a ver, foi a opção estética televisiva geral dominante, o que, segundo Pumarejo, implica uma documentalidade e facilita processos de identificação e projeção ao mostrar situações extrapoláveis à cotidianidade do telespectador. ${ }^{5}$

No caso do Brasil, esta busca da produção ficcional, de produzir imagens de um país real - e nele também de suas diferenças regionais -, é evidenciada tanto por esta retomada de autores literários como pela presença na televisão de autores nacionais. Os precursores da telenovela brasileira, Felix Caignet e Glória Magadan, são dos poucos, talvez os únicos, autores não brasileiros da nossa produção ficcional.

Uma certa insistência da televisão brasileira falar de um Brasil, ao menos de uma certa imagem dele, para os brasileiros, em termos da construção de um imaginário nacional, talvez tenha sido similar ao que fez o cinema norteamericano ao construir uma imagem da nação coletivamente compartilhada. Como o cinema brasileiro não teve o mesmo vigor em termos de edificar um produto cultural massivo com fortes doses de apelo popular e nacional, a televisão se ocupou desta tarefa.

A matéria-prima dos autores da produção ficcional televisiva tem sido as obras literárias que lhes são anteriores ou contemporâneas - no caso de adaptações; ou, então, as suas próprias experiências de vida nas metrópoles, principalmente Rio e São Paulo - Gilberto Braga, Aguinaldo Silva e Dias Gomes são exemplos notórios dessa apropriação artístico-televisiva do real; ou a

5 Segundo Lopez-Pumarejo, o modelo de representą̧̃̃o dramática dominante na comunicaçāo de ınassas tem sua base no naturalismo, o tipo de representação dramática mais popular, mais decodifićável. LOPEZ-PUMAREJO, Tomas. Aproximacion a la telenovela. Madrid: Catedra, 1983. p. 57. 
informação obtida nos jornais e na própria televisão - um modo de estarem sintonizados com o mundo a ser ficcionalizado em suas histórias e uma forma de o discurso jornalístico e televisivo sobre o real informar as construções do gênero ficcional.

A diretriz da TV Globo de alternar, no horário das oito, novela urbana e novela rural faz parte dessa estratégia de reconhecimento e de sintonia com os telespectadores, construída a partir do modo como o meio televisivo interpreta a existência de dois Brasis a serem conquistados em sua audiência. Neste sentido, o programa Brasil Legal, explorando uma nova linguagem, um misto de documentário e ficção narrado em tom de humor, aponta para esta redescoberta dos lugares ignorados de um país de tamanha dimensão geográfica e cultural.

Os produtos ficcionais telenovelas e seriados não só se nutrem dos episódios e temas da realidade exibida nos telejornais como também, ao abordarem questões contidas nas várias esferas dos debates contemporâneos, tornam-se, eles próprios, notícias. Num movimento inverso, passam a alimentar a pauta dos jornais e telejornais, como ocorreu com a exibição do seriado Decadência, escrito por Dias Gomes, transmitido em setembro de 1996 e que provocou matérias sobre a Igreja Universal, sobre os evangélicos, sobre mudanças políticas recentes etc., assim como anteriormente ocorrera na Globo zom Anos Rebeldes, transmitida em 1991.

Estas duas vias de intervenção da realidade sobre o (e a partir do) texto ficcional demonstram uma relação intertextual tão promíscua de modo a tornar impossível a fixação de fronteiras nítidas entre os dois universos. Estamos diante. de um processo de elaboração artística mimeticamente conectado com um real que passa a ser construído nas pautas da produção ficcional de um meio televisivo que informa e fertiliza, de forma simultânea e massiva - ao contrário do que sempre fez a literatura, por exemplo - a experiência social no mundo contemporâneo. Adiciona-se a isso a velocidade do meio televisivo de dar conta e de esgotar rapidamente muitos dos temas com que trabalha e o seu dom de ubiqüidade sem similares em outros meios comunicativos.

Certos conteúdos declaradamente informativos, quando expostos a partir de uma grade de programação televisiva que os aglutina numa certa ordem para expô-los, c das imposições das estratégias narrativas deste dispositivo, contagiam-se por formas ficcionais do narrar, particularmente as do drama, do sensacionalismo, da'espetacularização e da personalização. Tais contaminações, ao mesmo tempo que adicionam apelos aos conteúdos, provocam deficiências no seu caráter pretensamente informativo. $E$, de modo semelhante às estratégias dos textos ficcionais, preenchem vazios de informação e agregam dados e referências à realidade apoiando-se nos recursos da verossimilhança. 
.Estes procedimentos criam aproximações, produzem interlocuções e sintaxes entre os programas, num intertexto só possível no interior da própria televisão. Esta, por sua vez, não é imune a contágios, não só de outros meios e linguagens, como da própria realidade, apropriada como referência por ser a base comum da possibilidade de se produzir o ato comunicativo. Realidade apropriada, informada e exercitada pelo discurso televisivo, que sobre ela se despeja para reconstruí-la, reelaborá-la, redefini-la, produzindo-se novas interpretações, num movimento cíclico que está, a toda o tempo, por este comportamento discursivo, reconformando a experiência social e a percepção do receptor:

\section{O telejornal e o contar histórias}

Esse hibridismo da ficção e do real aparece ainda nos telejornais e nos documentários, quando o fato ou tema, ao ser transformado em notícia, é dramatizado, personalizado e sensacionalizado pelo tratamento editorial.

Os programas jornalísticos - basicamente os telejornais e os documentários - agendam seus temas e assim estabelecem suas maneiras de interagir com os assuntos públicos, muitas vezes ficcionalizando-os ao reportá-los. Com isso, a televisão agrega audiência e se estabelece como forma comunicativa de angariar legitimação e de se lançar como protagonista privilegiada com grande poder de desempenho na construção de valores públicos e de uma determinada ética.

Nesse sentido, a hipótese do agenda-setting auxilia no esclarecimento do modo como os meios de comunicação não só moldam o que pensamos sobre a realidade cxterior, mas definem, sobretudo, uma pauta daquilo sobre o que é necessário ter uma opinião e discutir. ${ }^{6}$ Assim, os telejornais, diante de um enorme e fragmentado conjunto de fatos e eventos cotidianos, lançam mão de suas rotinas estabelecidas e dos filtros já antecipadamente dados pelos seus valores-noticia ${ }^{7}$ para selecionar aqueles passíveis de serem formatados como

6 Para se compreender a hipótese do agenda-setting e o poder dos mass media de construir a imagem da realidade, ver WOLF, Mauro. Teorias da comunicą̧ão. Lisboa: Presenf̧a, 1987.

7 Robert Darnton afirma que "as matérias jornalísticas precisam caber em concepções culturais prévias relacionadas com a notícia", e, mais adiante, que "o contexto do trabalho modela o conteúdo da notícia, e as matérias também adquirem forma sob a intluência de técnicas herdadas de contar histórias". DARNTON, Robert. O beijo de Lamourette: mídia, cultura e revoluçũo. São Paulo: Companhia das Letras, 1990. p. 96-97. 
objetos de tratamento noticioso e daí passarem a freqüentar a agenda pública dos debates e das opiniões. ${ }^{8}$

Ao lançar notícias no espaço público mediado, a cobertura telejornalística, que num primeiro momento se apropriou do real para dele extrair a matéria-prima de seus conteúdos, passa a ser o sujeito de um movimento de intercessão nos próprios fatos noticiados - ou nos fatos públicos por sua própria natureza, ou nos fatos privados tornados públicos pela ação noticiosa. Deste modo, o tratamento editorial dramatizado e a focalização excessiva (artimanhas da sedução) em um fato influenciam de maneira decisiva seus desdobramentos, forma notória e poderosa da cobertura jornalística intervir sobre o real. ${ }^{9}$

Em artigo anterior ${ }^{10}$ analisei não só como as representações televisivas da violência e do crime propiciam uma imagem e valores gerais sobre a criminalidade, mas também como a superexposição do crime, dos criminosos e de suas vítimas tornam o telejornal, particularmente o Aqui Agora, uma instituição que representa ou ocupa o espaço de outras instituições: da polícia e da justiça, ao investigar, denunciar, julgar e estabelecer a sentença do crime (podendo-se considerar, neste caso, a exposição pública como um equivalente da pena judicial); e de uma instituição pedagógica e moral que informa a todo o momento sobre o certo $\mathrm{e}$ o errado. Atitude editorial em relação à violência que transforma alguns programas da televisão em tribunais mediáticos.

Esta imagem sobre a violência, construída nas pautas dos telejornais que a tratam tradicionalmente como um de seus temas preferidos, termina por

8 Para se compreender como as notícias são o produto final de um complexo processo que se inicia na escolha e seleção sistemática de acontecimentos, de acordo com um conjunto de categorias sociais previamente construídas, e o sentido que tem o valor-notícia para o jornalista, ver HALL, Stuart; CHRITCHER, Chas; JEFFERSON, Tony; CLARKE, John; ROBERTS, Brian. The social production of news: mugging in the media. In: COHEN, Stanley; YOUNG, Jock (Eds.). The manlufacture of news. Beverly Hills: Sage/London: Constable, 1985.

9 Tenho acompanhado com alguma curiosidade (mas sem nenhuma pesquisa mais sistemática) o episódio, dentre outros semelhantes, do julgamento do ex-jogador negro norteamericano O. J. Simpson, fartamente coberto por sete emissoras de televisão, dentre elas pela CNN. De um crime de homicídio duplo, semelhante a muitos outros crimes da mesma natureza, com exceçiio talvez da notoriedade do acusado, a cobertura transbordante dos meios de comunicação possibilitou que este fosse transformado numa questão pública, judicial e política, em que o assassinato em si perdeu relevância, embora fosse o fato propiciador do julgamento e das notícias. A intensa cobertura permitiu que emergissem no debate questōes raciais, da discriminação e do funcionamento da polícia e da Justiça norte-americanas, como também do uso mercadológico do caso feito, sobretudo, pelos próprios meios de comunicação. Interessa notar aqui que a exagerada cobertura dada ao julgamento tenha definido muitos de seus rumos e se desdobrado em outros fatos notadamente públicos.

10 RONDELLI, Elizabeth. Media, representações da violência, da criminalidade e açōes políticas. Comunicação \& Política, Rio de Janeiro, v. 1, n. 2, nova série, 1994. 
demandar ações políticas inspiradas por um certo imaginário da violência e do medo. No caso do tratamento dado à violência, percebe-se esta ligação entre a cobertura jornalística que se apropria do real e, ao se despejar narrativamente sobre ele, termina por condicionar reações políticas orientadas pela bússola da cobertura. Obviamente que a tematização da violência angulada desta maneira ocorre num país onde, apesar dos altos índices de violência e criminalidade, a prática da polícia e da justiça tem se mostrado, na maioria das vezes, falha ou ausente, por isso a grande importância desta outra prática de uma justiça mediática e vicária.

Embora possamos indagar sobre os princípios ideológicos e impositivos da construção dos telejornais, investigação tradicionalmente realizada por vários especialistas da área, o que talvez clame por uma certa atenção neste momento é esta conexão, enormemente facilitada pela cobertura telejornalística, estabelecida entre um episódio de caráter cotidiano e razoavelmente banal e a atenção pública que ele pode provocar. Deste modo, podemos pensar em um outro sentido para o termo 'mediação' - a ligação da experiência efêmera e cotidiana com as questões mais gerais que acabam sendo envolvidas nestes aspectos parciais da experiência. Ou, em outras palavras, esta capacidade que os media possuem de muitas vezes desprezarem assuntos notoriamente reconhecidos como de relevância pública, ao mesmo tempo que utilizam episódios triviais como pretexto para fazerem aflorar questões públicas submersas, a partir da exploração de episódios que contenham a potencialidade de criar o interesse geral de leitores ou telespectadores. Tais episódios triviais, por sua vez, podem se transformar num fato político importante a partir da repercussão social que sua divulgação angarie, mesmo que tenha se originado do ato de ter sido apresentado apenas como uma boa história."

Como nunca estamos livres dos efeitos perversos, o tratamento noticioso pode produzir duas tendências paradoxais: trazer para a cena pública eventos sem importância que consigam arrebatar a opinião pública, ou trazer uma exagerada cobertura de eventos públicos importantes que, no entanto, pela assiduidade e repetição de sua ocorrência no noticiário podem se tornar fatos

11 Em Jornalismo fin-de-siècle (São Paulo: Scritta Editorial, 1993. p. 105), Ciro Marcondes considera que a "[...] prática jornalística toma-se, neste novo momento, a da imprensa minimalista. Os grandes assuntos são tratados como se reduzissem a questōes subjetivas de caráter pessoal. A economia não é trabal hada do ponto de vista de sua relação com o Estado, coma sociedade maior, da perspectiva das tendências e rumos, enquanto organicidade do sistema. [...] Há um reducionismo dos grandes temas a assuntos de natureza subjetiva, individual ou particular." Pretendemos considerar se essa prática, a que ele chama minimalista, não foi sempre a tônica do jornalismo na sua arte de contar histórias, e se tal prática, em muitos casos, não é a que permite conectar assuntos de natureza privada com aqueles de natureza pública, expondo a indissociabilidade entre estes dois pólos. 
banalizados, diante dos quais a atenção, então já saturada e anestesiada, não mais se detém. Paradoxo que não nos oferece necessariamente nenhuma certeza sobre os efeitos de uma cobertura jornalística e dos modos como pode interceder sobre o real, pois talvez não haja uma medida exata para se afirmar se são as histórias contadas ou o modo de contá-las o que necessariamente torna um fato importante aos olhos do público.

A televisão, este dispositivo discursivo que muito pode conter e contar, estabelece oùtras estratégias, estas não propriamente entre os textos ficcionais e jornalísticos, localizadas numa região propositadamente obscura: são as inserções publicitárias ou político-promocionais que se escamoteiam como tais nos discursos apresentados, a princípio, como jornalísticos - cujo compromisso seria o de apresentar informação, a mais objetiva, sobre a realidade. Tais inserções que, por vezes, também aparecem em textos ficcionais se utilizam de uma certa atitude despretensiosa e despreocupada do telespectador para, literalmentc, venderem opiniões e informações. Uma estratégia de usar, ou abusar, da confiabilidade depositada pelo receptor ao que Ihe é apresentado para lhe dirigir informações de natureza e objetivos duvidosos quanto à sua veracidade, embora revestidos com tal verniz.

Por outro lado, os meios de comunicação, ao se colocarem como dispositivos dos fatos - as histórias -, têm a virtualidade de exporem também um número infinnito de versões - outras histórias - buscando estabelecer sentidos sobre a natureza dos fatos. O que não deixa de ser uma forma polifônica de os meios se relacionarem com o fato ou a história original ao exporem pontos de vista contraditórios, díspares, dissonantes, aberrantes, embora todos referidos à história originalmente exposta pelos jornais e telejornais. Aqui a suposta existência de um exercício livre e polifônico das interpretações pode ser contestado pelo argumento de que a simultaneidade das várias vozes, embora independentes, desenvolvem-se a partir de um mesmo referencial - todas partem de um mesmo conjunto de fatos, previamente eleitos, postos à discussão pública.

No caso da televisão, essa sedução exercida pelo contar histórias é incrementada pelas possibilidades da linguagem do próprio meio. Dentre muitas, sua ênfase na oralidade (lembremos que sempre há uma matriz oral numa boa história); a simultaneidade entre o acontecer e sua divulgação, o que torna os relatos mais excitantes porque desconhecidos; a presença da imagem que opera não só como testemunha, mas acrescenta possibilidades ao olhar que não cabem no relato oral; a possibilidade de aproximação a uma linguagem teatral, em que a performance sempre emerge como ato possível; o sentido da veracidade trazido pelas cenas ao vivo; os recursos de edição que trabalham som (música), imagem e presença de narradores distintos em diferentes locais, relatando o fato de diversos pontos de vista. 
Esses elementos tornam as histórias mais palatáveis a um público, no caso brasileiro, basicamente iletrado, porém habilitado na prática de ver televisão, pouco familiarizado com o narrar literário que cultiva muitos dos elementos narrativos que a televisão (e o cinema) consegue massivamente exercitar.

Além disso, na televisão o ato de narrar histórias ou notícias tem a possibilidade de produzir, se não a idéia da verdade, ao menos da verossimiIhançă. A expressão "aqui agora" traduz esta pretensão de afirmar a fidedignidade do que é mostrado ao vivo num determinado tempo e lugar. Um Ȧqui Agora que produziu certas comoções por mostrar cenas de um Brasil insólito que não estava contido nas imagens assépticas de outras emissoras ou programas, e por utilizar uma estética do grotesco, similar à estética dos "pobres, sujos e malvados" que freqüentam a vida real de nossas ruas. É uma estética televisiva do SBT, um contraponto ao estilo clean da Globo, onde os pobres só podem ser. representados nas telenovelas como caricaturas.

\section{Narrativas televisivas e mitos}

Notícias e mitos são narrativas social e culturalmente construídas. Embora cada uma delas tenha sua especificidade de produção e de recepção, as similaridades permitem um olhar antropológico sobre ambas. Se assim as entendermos, não precisamos tomar as notícias exatamente como relatos objetivos da rcalidade, mas como representações ou expressões culturais elaboradas no processo de vida cultural. Embora, neste caso, possamos falar de uma graduação do caráter objetivo do relato - há notícias que se aproximam mais da expressão mítica de uma sociedade. Barthes já nos revelou esta vocação dos mass media de formularem mitologias.

As notícias, como os mitos, ajudam a ordenar o caos do mundo da experiência social. ${ }^{13}$ São peças de um sistema simbólico que atuam como modelo desta e para esta experiência. Como os mitos, podem ser um dos lugares por onde se adentra esta cultura, cujas formas de um narrar para o coletivo encontram-se expostas cotidianamente nos jornais e, sobretudo, na televisão, este grande recipiente de histórias contemporâneas - a Scherazade de nossos

12 BARTHES, Roland. Mitologias. São Paulo: Difel, 1987.

I3 BIRD, S. Elizabeth; DARDENNE, Robert W. Myth, chronicle and story: exploring the narrative qualities of news. In: CAREY, J. W. (Ed.) Media, myths and narratives: television and the press. Newbury Park: Sage, 1988. Neste artigo os autores remetem a uma extensa bibliografia sobre esta relaçĩo entre mito, notícias e história. 
tempos. Histórias que atravessam fronteiras locais e nacionais na sua forma de acontecer e ser recebida.

Silverstone ${ }^{14}$ considera que os textos apresentados pela televisão, suas imagens, narrativas, ícones e rituais são o lugar da cultura mítica contemporânea. Embora inadequadamente, a televisão ocupa o espaço e cumpre a função do mito na sociedade contemporânea. Em termos durkheiminianos, Silverstone afirma que a televisão proporciona um fórum e um focus para a mobilização da energia e do entusiasmo coletivos na apresentação de eventos nacionais, por exemplo.

Alertando que a comunicação não é só mito ou toda mito, mas tocada pelo mito, o autor sugere que assistir televisão é um rito de passagem: o telejornal da noite, por exemplo, leva-nos do familiar ao estranho e deste para o familiar. Relacionamo-nos com a televisão de modo mágico. As fronteiras entre realidade e fantasia são constantemente transgredidas. Alguém já observou que na televisão, como na fábula, admitimos com naturalidade que os animais falem.

Mitos e notícias têm na retórica a sua "tecnologia do apelo", nas palavras de Silverstone. ${ }^{15}$

Retórica é linguagem em ação, o uso da linguagem como meio simbólico para induzir cooperação de seres cuja natureza responde a símbolos. A retórica tem uma dimensão estética e política: para agradar e para comandar. Nem todos os programas televisivos requerem ação, num sentido direto (embora a publicidade e as transmissōes dos partidos políticos o façam), mas requerem atenção [...]. Em sua formalidade, sua familiaridade, sua efemeridade, seu status como um texto público, a televisão é um meio retórico por excelência. ${ }^{16}$

\section{A televisão dos documentários e dos relatos íntimos}

Segundo Barthes, o fascínio da nossa civilização pelo "efeito" de realidade explicaria não só a autoridade do historiador como também a obsessão da história positivista de repetir "isso ocorreu”. Para ele, esta tendência também esclareceria a moda do romance realista, do diário íntimo, da literatura docu-

14 SILVERSTONE, Roger. Television myth and culture. In: CAREY, James W. Media, $m y t / s . . ., p .21-47$.

15 Ibid., p. 34.

16 Ibid., p. 34-35. 
mental. do museu histórico, da exposição de antigüidade, do desenvolvimento massivo da folografia. ${ }^{17}$

Podemos acrescentar a essas modas, pela pista deixada pela fotografia, a programação televisiva, particularmente os telejornais; c pela pista deixadal pelo diário íntimo, os programas de entrevistas que inundam o horário de emissão. ${ }^{18}$ Esses programas são compostos por narrativas do eu, histórias ou microistórias de vida de indivíduos famosos ou não, narradas com sinceridade e com o apoio de um entrevistador, por quem efetivamente as viveu c cstá ali para lhes atribuir veracidade c, através da exibição na tela, conferir-lhes uma dimensão pública. Espaço de veracidade, ou de sua simulação, que muitas vezes é apropriado pelo mundo político e artístico interessados na autopromoção de seus membros.

Os programas televisivos alimentam este duplo fascínio pela vida lá fora. Ao exihir cenas de outros países, do mundo da política, da guerra, dos lenômenos climáticos e meteorológicos, a televisão satisfaz o interesse e a curiosidade por conhecer através dos documentários e dos telejornais. Como alimenta também essa curiosidade sobre as microbiogralias de individuos e suas histórias trágicas ou divertidas, narradas nos programas de entrevistas que revelam uma televisão do monólog̣o, do diálogo e dá expressão oral, onde os efeitos de edição intervêm de modo limitado.

Através dos programas de entrevistas, mais uma vez a televisão faz cssa conexão entre os microrrelatos individuais do cotidiano e os eventos sociais de alguma importância. Um modo de falar da cultura, subjetivando-a, através da estratégia de focalizar os indivíduos que efetivamente vivenciam experiências sociais. Experiências que podem ser ditas por eles próprios, ou conduzidas atlavés de um narrador, um exímio contador de histórias, que extrai dos casos particulares o desenho de uma experiência cotidiana c coletiva mais ampla, semelhante a muitas outras.

17 BARTHES. Roland. El discurso de la historia. In: Estructuralismo y litcratura. Buenos Aircs: Ediciones Nueva Visión, 1970. p. 49.

is Levantamento realizado na programação do mês de junho de 1995 revelou a existência, nos canais que transmitem em rede no Rio de Janeiro, de 29 títulos de programas de entrevistas, gue totalizam 94 prograunas scmanais octupando aproximadamente 115 horas da programaçióo semanal das emissomits TVE, Manchete, Bandeirantes, CNT, SBT e Record. 


\title{
RESUMO
}

Análise da maneira como alguns programas televisivos transitam em mão dupla entre os universos da realidade e da ficção, produzindo, para a construção de suas narrativas, ficções sobre os fatos do real, ou dando tons de realidade ao universo da ficção, em que o uso da imagem e outras operações intertextuais garantem a produção da verossimilhança. Neste sentido, real e ficcional são mutuamente fertilizados, conferindo especificicidades próprias à ação pedagógica da televisão, que através da construção de seus temas passa a se inserir no debate público e na construção da experiência social contemporâneit.

Palavras-chave: televisão, discurso, ficção.

\begin{abstract}
It analyzes the way how some television's programs convey in both ways between the universe of reality and the universe of fiction making, for the construction of its narratives, fictions about the real facts or giving real touch to the universe of fiction with the use of image and others intertextual operations which provide the productions with verisimilitude. In this sense, "reality" and "fiction" are mutually fertilized, confering proper specifications upon the pedagogical action of television which through the construction of its themes starts to put itself in the public debate and in the construction of a contemporary social experience.
\end{abstract}

Key words: television, discourse, fiction. 